\title{
Correction to: Attention-deficit/hyperactivity disorder and lifetime cannabis use: genetic overlap and causality
}

\author{
María Soler Artigas $(\mathbb{D}$ - Cristina Sánchez-Mora 1 - Paula Rovira - Vanesa Richarte - Iris Garcia-Martínez • \\ Mireia Pagerols - Ditte Demontis 1 - Sven Stringer - ADHD Group of the Psychiatric Genomics Consortium, \\ International Cannabis Consortium - Jacqueline M. Vink (1) Anders D. Børglum - Benjamin M. Neale (i) - \\ Barbara Franke (i) - Stephen V. Faraone 1 - Miguel Casas - Josep Antoni Ramos-Quiroga • Marta Ribasés
}

Published online: 24 February 2021

(c) The Author(s), under exclusive licence to Springer Nature Limited 2021

Correction to: Molecular Psychiatry https://doi.org/10.1038/s41380-018-0339-3

Following publication of this article, Benjamin M. Neale contacted the journal to request the addition of the following text to the 'Conflict of Interest' declaration: 'B.N. is a member of the scientific advisory board at Deep Genomics and RBNC
Therapeutics and a consultant for Camp4 Therapeutics, Takeda Pharmaceutical and Biogen'. In addition, the genetic correlation presented in the abstract should be $\mathrm{rg}=0.29$ rather than $r^{2}=0.29$ and the discussion should estate that that winner's curse could have led to an underestimation of the causal estimate, rather than an inflation. This has now been corrected in both the PDF and HTML versions of this article. 